\title{
Visualization of Borrelia burgdorferi sensu lato by fluorescence in situ hybridization (FISH) on whole-body sections of Ixodes ricinus ticks and gerbil skin biopsies
}

\author{
Bettina Hammer, ${ }^{1}$ Annette Moter, ${ }^{1}$ Olaf Kahl, ${ }^{2}$ Gerd Alberti ${ }^{3}$ \\ and Ulf B. Göbel ${ }^{1}$
}
1 Institut für Mikrobiologie und Hygiene, Universitätsklinikum Charité, Humboldt- Universität zu Berlin, Dorotheenstraße 96, D-10117 Berlin, Germany
2 Institut für Biologie, Angewandte Zoologie/Ökologie der Tiere, Freie Universität Berlin, Haderslebener Straße 9, D-12163 Berlin Germany
3 Zoologisches Institut und Museum, Ernst-Moritz- Arndt-Universität, J.-S.- Bachstraße 11/12, D-17487 Greifswald, Germany

\author{
Author for correspondence: Bettina Hammer. Tel: +4930450 524074. Fax: +4930450524902. \\ e-mail : bettina.hammer@charite.de
}

The objective of this study was to visualize borreliae directly in whole-body sections of Ixodes ricinus by fluorescence in situ hybridization (FISH). Borrelia afzelii mono-infected or Borrelia burgdorferi sensu stricto (ss)/B. afzelii doubleinfected nymphs were fixed, embedded in cold polymerizing resin and sectioned. The same sample processing was applied to skin biopsies taken from a Mongolian gerbil after an infectious tick-bite. FISH was carried out using 16S-rRNA-directed, fluorescence-labelled oligonucleotide probes specific for the genus Borrelia and specific within the group of Lyme borreliosisassociated genospecies B. afzelii, B. burgdorferi ss, Borrelia garinii and Borrelia valaisiana. Sensitivity and specificity of the newly designed probes were evaluated using PCR, dot-blot hybridizations and FISH. Despite significant autofluorescence of certain tick tissues (which allowed good histological orientation within the sections), borreliae showing the typical spirochaetal morphotype were clearly visible in five out of six putatively infected ticks. These findings were confirmed by electron microscopy of ticks from the same infected batch as used for FISH. Attempts to produce ticks infected by two different Borrelia genospecies were not successful. FISH on whole-body sections of resin-embedded ticks offers the possibility of visualizing and identifying borreliae within tick tissues. This technique has great potential for the investigation of the transmission of bacteria or other micro-organisms by arthropod vectors. Furthermore, clear visualization of single spirochaetes distributed along subcutaneous fat cell membranes in gerbil skin biopsies suggests that FISH might also be suitable for the detection of borreliae in clinical tissue specimens.

Keywords: Lyme borreliosis, arthropods, mixed infection, in situ hybridization, FISH

\section{INTRODUCTION}

Borrelia burgdorferi sensu lato (sl), causing Lyme borreliosis (LB) is transmitted by and to Ixodes ticks (Acari, Ixodidae) during their blood meals on vertebrate hosts. Three Borrelia genospecies, Borrelia afzelii, Borrelia garinii and B. burgdorferi sensu stricto (ss) cause human infection and disease. The pathogenicity of Borrelia valaisiana for humans is assumed (Rijpkema et

Abbreviations: EM, electron microscopy; FISH, fluorescence in situ hybridization; IFA, indirect immunofluorescence assay; LB, Lyme borreliosis; sl, sensu lato; ss, sensu stricto. al., 1997). Each of these bacteria is transmitted by Ixodes ricinus, the main vector tick in Europe. In contrast, in North America, human LB seems to be caused exclusively by $B$. burgdorferi ss transmitted by Ixodes scapularis in the East and Ixodes pacificus in the West. Although the general borrelial migration pattern within infected Ixodes ticks during feeding from the tick midgut via the salivary glands into the vertebrate host seems to be the same in I. ricinus and I. scapularis (Benach et al., 1987; Burgdorfer et al., 1989; Piesman et al., 1991; Piesman, 1995; Gern et al., 1996), recent investigations addressing the risk of $B$. burgdorferi sl transmission by these tick species revealed intriguing differences. It was 
shown that nymphal $I$. ricinus can transmit borreliae earlier during the blood meal than has been known from I. scapularis nymphs (Kahl et al., 1998a). Interestingly, borreliae were found distinctly more often in the salivary glands of unfed $I$. ricinus than in unfed $I$. scapularis (Leuba-Garcia et al., 1994; Lebet \& Gern, 1994; Korenberg \& Moskvitina, 1996). The reason(s) for these differences are as yet unknown and need further investigation.

The aim of the present study was to visualize borreliae in sections of infected vector ticks to show their spatial distribution. This was achieved by fluorescence in situ hybridization (FISH) using Cy3-labelled oligonucleotide probes. FISH allows simultaneous visualization and identification of micro-organisms in their natural microhabitat. This method has been applied to a variety of environmental and clinical specimens (Amann et al., 1996; Snaidr et al., 1997; Schuppler et al., 1998; Trebesius et al., 1998; Fritsche et al., 1999; for a review see Moter \& Göbel, 2000). There have also been reports on its use to identify bacteria within infected tissues (Forsgren et al., 1994; Berlau et al., 1998; Trebesius et al., 1998; Jansen et al., 1999; Harmsen et al., 2000; Hogardt et al., 2000). Recently, FISH was applied to biopsies of digital dermatitis lesions embedded in cold polymerizing resin, allowing sectioning of the tissue with excellent histological conservation (Moter et al., 1998). We adapted this protocol for use on ticks and designed oligonucleotide probes specific within the genus Borrelia and within the group of LB-associated genospecies B. afzelii, B. burgdorferi ss, B. garinii and B. valaisiana. PCR, dot-blot hybridization and FISH were performed to test the respective probes. This is the first report to investigate the spatial distribution of borreliae in whole-body sections of I. ricinus by FISH. To evaluate the newly developed technique, individuals from the same tick batch were investigated by indirect immunofluorescence assay (IFA) and electron microscopy (EM). To prove suitability of the procedure for clinical samples, we also applied the method to a skin biopsy of a Mongolian gerbil, previously infected by $B$. afzelii via tick-bite.

\section{METHODS}

Bacterial strains. B. afzelii strains $A Z / 2$ and $A Z / 10$ were originally from field-collected $I$. ricinus nymphs and were subsequently maintained by alternating between Mongolian gerbils (Meriones unguiculatus) and ticks for 5 years (four gerbil passages) and 3.5 years (two gerbil passages), respectively. B. burgdorferi ss-infected I. scapularis nymphs were field-collected in Westchester county (New York State, USA) and kindly provided by D. Fish (Yale School of Medicine, Epidemiology and Public Health, New Haven, CT, USA). The identity of the respective borrelial strains was confirmed by PCR and dot-blot hybridizations. Strain AZ/2 was identified by PCR as B. afzelii by S. Rijpkema (National Institute of Public Health and the Environment, Bilthoven, The Netherlands) (Rijpkema et al., 1995). In addition, Borrelia isolates were obtained from individual ticks cultured in BSK$\mathrm{H}$ medium (Sigma-Aldrich). OspA serotyping using these isolates was carried out by B. Wilske (Max von Pettenkofer
Institute for Hygiene and Medical Microbiology, Munich, Germany) to confirm the strains as B. afzelii or B. burgdorferi ss (Wilske et al., 1993).

The following cultured Borrelia and Treponema strains were included as controls in FISH [cells fixed in PBS $(137 \mathrm{mM}$ $\mathrm{NaCl}, 2 \cdot 7 \mathrm{mM} \mathrm{KCl}, 10 \cdot 14 \mathrm{mM} \mathrm{Na}_{2} \mathrm{HPO}_{4}, 1.76 \mathrm{mM} \mathrm{KH}_{2} \mathrm{PO}_{4}$ ) with $3.7 \%, \mathrm{v} / \mathrm{v}$, formaldehyde] and PCR experiments: $B$. burgdorferi ss (B31 ${ }^{\mathrm{T}}$; tick isolate, USA, ATCC 35210), B. garinii (A; tick isolate, R. Ackermann, University Hospital of Cologne, Cologne, Germany), B. afzelii (PKo; human skin isolate, B. Wilske), B. valaisiana $\left(\mathrm{VS}_{116^{\mathrm{T}}}\right.$; tick isolate, Switzerland, kindly provided by D. Postic, Institut Pasteur, Paris, France), Borrelia hermsii ( $\mathrm{HS}^{\mathrm{T}}$; tick isolate, USA) and Treponema denticola (ATCC 33521).

Ticks and tick infection. Two batches of laboratory-reared proven Borrelia-negative I. ricinus ticks (second laboratory generation) were each in vivo-infected during their larval blood meal on a Mongolian gerbil previously fed upon by four I. ricinus nymphs infected with the local $B$. afzelii strains $\mathrm{AZ} / 10$ and $\mathrm{AZ} / 2$. Briefly, four infected ticks were placed onto each gerbil to feed to repletion. Two to three weeks after gerbil infection, approximately 100 unfed proven Borrelianegative $I$. ricinus larvae (at least second laboratory generation) were fed on each gerbil. The fully engorged larvae were allowed to molt to the nymphal stage under quasinatural temperature and photoperiodical conditions and were analysed for borreliae by IFA some weeks or months after nymphal ecdysis. To produce I. ricinus nymphs infected both with $B$. afzelii and $B$. burgdorferi ss, tick-naive gerbils were infected by feeding of I. ricinus nymphs infected with $B$. afzelii strain $\mathrm{AZ} / 2$ and $27 \mathrm{~d}$ later feeding of B. burgdorferi ssinfected $I$. scapularis nymphs. In a second experiment, the sequence of infection was reversed: feeding of $B$. burgdorferi ss-infected $I$. scapularis nymphs and $45 \mathrm{~d}$ later feeding of $B$. afzelii (strain AZ/2)-infected I. ricinus nymphs. Subsequently, larval xenodiagnosis was performed on each gerbil to produce double-infected $I$. ricinus ticks. To evaluate the tick infection rate, 10 individuals of each resultant nymphal batch were screened for borreliae by IFA as described by Kahl et al. (1992) using a polyclonal antibody (rabbit hyperimmune serum against the $B$. garinii strain $1 \mathrm{~B} 29$, kindly provided by $\mathrm{A}$. Schönberg, Federal Institute for Health Protection of Consumers and Veterinary Medicine, Berlin, Germany). Six resultant xenodiagnostic I. ricinus nymphs were analysed by PCR and dot-blot for the identification of mixed infections with B. afzelii and B. burgdorferi ss.

Gerbil skin biopsy. A skin punch biopsy from a gerbil was taken at the attachment site of a single I. ricinus nymph within the first $15 \mathrm{~h}$ after drop-off. This nymph belonged to the same $B$. afzelii-infected tick batch as used for FISH experiments (strain AZ/10). A second skin biopsy was taken in a distance of $1.5 \mathrm{~cm}$ from the tick-bite site as a putative negative control.

PCR. To identify the Borrelia genospecies and to detect Borrelia double infections within the produced tick batches, ticks were analysed by PCR using Borrelia genus-specific amplification of $16 \mathrm{~S}$ rDNA and subsequent dot-blot hybridization. Ticks were individually processed for PCR by washing them twice in sterile distilled water and crushed in $100 \mu \mathrm{l} 12.5 \%$ (w/v) Chelex 100 (Bio-Rad), as described by Maiwald (1996) with some modification. In brief, tubes with the crushed ticks were heated at $56^{\circ} \mathrm{C}$ for $15 \mathrm{~min}$ and at $100{ }^{\circ} \mathrm{C}$ for another $10 \mathrm{~min}$, vortexed thoroughly and chilled on ice. The samples were then centrifuged at $7000 \mathrm{~g}$ for $12 \mathrm{~min}$ and $5 \mu \mathrm{l}$ of the supernatant was directly used for PCR or stored at $-80{ }^{\circ} \mathrm{C}$ until further use. DNA preparation from cultured borreliae or treponemes was carried out according to standard protocols (Sambrook et 
FISH on Borrelia-infected Ixodes ricinus ticks

Table 1. Oligonucleotide probes

\begin{tabular}{|llllll|}
\hline $\begin{array}{l}\text { Oligonucleotide } \\
\text { probe }\end{array}$ & \multicolumn{1}{c}{$\begin{array}{c}\text { Standardized } \\
\text { probe name* }\end{array}$} & \multicolumn{1}{c|}{ Specificity } & \multicolumn{1}{c|}{ Sequence $\left.\mathbf{5}^{\prime}-\mathbf{3}^{\prime}\right)$} & Position $\dagger$ \\
\hline EUB338 & S-D-Bact-0338-a-A-18 & Bacteria & GCTGCCTCCCGTAGGAGT & $338-355$ & Fluorescein \\
Borr4 & S-G-Borr-1068-a-A-21 & Genus Borrelia & CCAACACCTCACAGCACGAGC & 1068-1088 Fluorescein, Cy3 \\
BaV1 & S-LB-Ba-80-a-S-22 & B. afzelii & GCAATACATTTAGTGGCGAACG & $80-101$ & Digoxigenin \\
reBaV1 & S-LB-Ba-80-a-A-22 & B. afzelii & CGTTCGCCACTAAATGTATTGC & $80-101$ & Cy3 \\
BbV1 & S-LB-Bb-80-a-S-19 & B. burgdorferi ss & GCAATACATTCAGTGGCGA & $80-98$ & Digoxigenin \\
reBbV1 & S-LB-Bb-80-a-A-21 & B. burgdorferi ss & GTTCGCCACTGAATGTATTGC & $80-100$ & Fluorescein, Cy3 \\
BgV1 & S-LB-Bg-117-b-S-21 & B. garinii & GATGATCTACCTACGAGATGG & $117-137$ & Digoxigenin \\
reBgV1 & S-LB-Bg-117-b-A-21 & B. garinii & CCATCTCGTAGGTAGATCATC & $117-137$ & Cy3 \\
BV & S-LB-Bv-77-a-S-21 & B. valaisiana & GTAGTAATACATCTAGTGGCG & $77-97$ & Digoxigenin \\
reBV & S-LB-Bv-77-a-A-21 & B. valaisiana & CGCCACTAGATGTATTACTAC & $77-97$ & Cy3 \\
\hline
\end{tabular}

*Standardized probe names according to Alm et al. (1996). LB indicates group of Lyme-borreliosis-associated borreliae.

† Numbering according to E. coli $16 \mathrm{~S}$ rRNA.

al., 1989). After comparative sequence alignment (see below) a primer set for amplification of B. burgdorferi sl $16 \mathrm{~S} \mathrm{rDNA}$ was designed: Borr0 (5'-GGC-AGT-GCG-TCT-TAA-GCATGC-3', corresponding to position 42-62 in the Escherichia coli 16S rRNA gene) and Borr4 (5'-CCA-ACA-CCT-CACAGC-ACG-AGC-3', corresponding to position 1068-1088). To check its suitability for PCR experiments we used the program OLIGO (version 4.0). The PCR reaction was performed in a $50 \mu \mathrm{l}$ mixture containing $30 \mathrm{mM}$ Tricine, $50 \mathrm{mM}$ $\mathrm{KCl}, 2 \cdot 5 \mu \mathrm{g}$ acetamide according to Barns et al. (1994), $15 \mathrm{pmol}$ of each primer (Tip Molbiol), $0.05 \mathrm{mM}$ of each nucleotide (Pharmacia), $2 \mathrm{mM} \mathrm{MgCl}$ and $1.25 \mathrm{U}$ AmpliTaq polymerase (Perkin-Elmer). Concentrations of $\mathrm{MgCl}_{2}$, primers, nucleotides and the amplification protocol were optimized as described by Cobb \& Clarkson (1994). Amplification conditions consisted of an initial denaturation step at $94{ }^{\circ} \mathrm{C}$ for $4 \mathrm{~min}$, followed by 30 cycles of $92{ }^{\circ} \mathrm{C}$ for $1.5 \mathrm{~min}, 62^{\circ} \mathrm{C}$ for $1.5 \mathrm{~min}$ and $72{ }^{\circ} \mathrm{C}$ for $2 \mathrm{~min}$, and a final extension step at $72{ }^{\circ} \mathrm{C}$ for $5 \mathrm{~min}$. The amplification products were detected by agarose gel electrophoresis $(1.5 \%)$. To assess the sensitivity of the PCR reaction, serial dilutions of template DNA ranging from $10 \mathrm{ng}$ to $1 \mathrm{fg}$ were produced. In addition, the cell content of borrelial cultures (strains A, PKo, B31 $1^{\mathrm{T}}$ and $\mathrm{VS} 116^{\mathrm{T}}$ ) was examined by dark-field microscopy using a counting chamber (Neubauer). Cultures were diluted in double-distilled water to reach a number of 1000 spirochaetes per $10 \mu \mathrm{l}$ and stored at $-80^{\circ} \mathrm{C}$. Aliquots of this solution containing 1000 spirochaetes were added to separate DNA preparation tubes each containing a Borrelia-negative I. ricinus nymph and $12.5 \%$ $(\mathrm{w} / \mathrm{v})$ Chelex solution to a final volume of $100 \mu \mathrm{l}$. For PCR, $0.5,2.5$ and $5 \mu$ of these Chelex-preparation supernatants was used, corresponding to 5,25 and 50 spirochaetes, respectively. Both the cell counting procedure and PCR were repeated at least twice for each human-pathogenic Borrelia genospecies. The sensitivity of the method for mixed DNA templates of $B$. burgdorferi genospecies was tested for serial dilutions ranging from 100 to 1 pg DNA.

Oligonucleotide probes for FISH and dot-blot hybridization. Five Borrelia-specific oligonucleotide probes directed to the $16 \mathrm{~S}$ rRNA were designed after comparative sequence analysis of $16 \mathrm{~S}$ rRNA sequences of respective type strains (B. burgdorferi sl) and/or well characterized strains of each genospecies, using the program CLUSTAL of the HUSAR 4.0 program package (Deutsches Krebsforschungszentrum, Heidelberg, Germany), (Table 1). Subsequently, selected probes and primer sequences were compared to all $16 \mathrm{~S}$ rRNA entries in the EMBL and GenBank databases (September 2000) using the FASTA program (HUSAR 4.0). The oligonucleotide sequences were further checked for their suitability by the program OLIGo 4.0. However, since each of these oligonucleotide probes except $\mathrm{BV} / \mathrm{reBV}$ shows sequence homology to at least one non-target Borrelia-species within the $B$. burgdorferi species complex (Table 2), we describe the designed oligonucleotide probes as specific within the group of LB-associated genospecies. One exception was found: database analysis revealed homology between $\mathrm{BgV} 1 / \mathrm{reBgV} 1$ and $\mathrm{a}$ single strain identified as B. afzelii (J1; GenBank accession no. L46697). However, at the probe position this strain is homologous to B. garinii published strains (e.g. accession nos X85198, X85193, X85199, D67018). In FISH experiments, the reverse primer Borr 4 was used as an alternative genus-specific probe. In other experiments, it was added together with a LBgroup-specific Borrelia probe to enhance signal intensities by multiple labelling according to Lee et al. (1993). All probes used for FISH were synthesized commercially and $5^{\prime}$ endlabelled with fluorescein or $\mathrm{Cy} 3$ (indocarbocyanine; Interactiva). The fluorescein-labelled Bacteria-specific probe EUB338 (Amann et al., 1990) (Tip Molbiol) was used as a control. To enhance the signal-to-noise ratio, we included a second green fluorescent dye, FluoX, for the labelling $\left(5^{\prime}\right)$ of EUB338 (Interactiva). Probes for dot-blot hybridizations were labelled by adding digoxigenin-labelled nucleotides and terminal transferase according to the manufacturer's recommendations (Boehringer Mannheim; see Table 1).

Dot-blot hybridization. Borrelia genus-specific amplicons were analysed by dot-blot hybridization using digoxigeninlabelled oligonucleotide probes as described by Moter et al. (1998). Aliquots $(5 \mu \mathrm{l})$ of the amplified products, including negative (PCR-negative control) and positive (B. afzelii, $B$. burgdorferi ss, B. garinii and B. valaisiana) controls, were transferred to positively charged nylon membranes (Boehringer Mannheim) and fixed by UV cross-linking. For subsequent use, filters were stripped by removing bound probes with $0 \cdot 2 \mathrm{M} \mathrm{NaOH} / 0 \cdot 1 \%$ SDS, dried and stored at $4{ }^{\circ} \mathrm{C}$.

FISH. Processing of biopsy specimens and fixed bacteria was carried out as described by Moter et al. (1998). A pretreatment of the ticks was necessary. Putatively B. afzeliipositive $(n=6)$ and Borrelia-negative $(n=5)$ unfed I. ricinus 
Table 2. Homology of the oligonucleotide sequences within the $B$. burgdorferi species complex

\begin{tabular}{|lccccc|}
\hline $\begin{array}{l}\text { Borrelia } \\
\text { genospecies }\end{array}$ & reBaV1 & reBbV1 & reBgV1 & reBV & Borr4 \\
\hline B. afzelii & & & & & \\
B. burgdorferiss & - & - & - & - & + \\
B. garinii & - & + & - & - & + \\
B. valaisiana & - & - & + & - & + \\
B. lusitaniae & - & - & - & + & + \\
B. japonica & + & - & + & - & + \\
B. tanukii & - & - & $+*$ & - & + \\
B. turdi & - & + & - & - & + \\
B. andersonii & - & + & - & - & + \\
B. bissettii & - & + & - & - & + \\
\hline
\end{tabular}

*With the exception of one strain (GenBank accession no. D67020).

nymphs were opened at the posterior part of their opisthosoma using a razor blade or needle and fixed with $3.7 \%$ formaldehyde in PBS for at least $12 \mathrm{~h}$ at $4{ }^{\circ} \mathrm{C}$. Embedding in cold polymerizing resin (polymerizing temperature $11^{\circ} \mathrm{C}$; Technovit 8100, Heraeus Kulzer) was performed according to the manufacturer's instructions. Polymerized resin blocks were stored at $4{ }^{\circ} \mathrm{C}$. Semi-thin tick sections $(4 \mu \mathrm{m})$ were obtained with a steel knife with hard metal edges on a rotary microtome (type 0036DDM; Medim), floated on sterile water, collected on silanized (3-aminopropyltrimethoxysilane; Sigma-Aldrich) microscope slides (Menzel-Gläser) and airdried. Sections were stained with haematoxylin/eosin to correlate the histology with structures recognized by autofluorescence. In situ hybridization was carried out as described previously (Moter et al., 1998) with slight modifications: hybridization buffer contained $20 \%$ (v/v) formamide, and slides were rinsed only once with sterile double-distilled water after hybridization. In each experiment, fixed cells of cultured spirochaetal strains as well as Borrelia-negative tick sections were included as controls. At least three sections per tick were analysed. Hybridized sections were examined with an epifluorescence microscope (Zeiss Axioskop) equipped with a $50 \mathrm{~W}$ high-pressure mercury lamp (HBO50; Osram) at $\times 100$, $\times 400$ and $\times 1000$ magnification. Narrow-band filter sets HQF41-007 and HQ-F41-001 (AHF) were used to observe fluorescein and FluoX, and Cy3 signals, respectively. Photomicrographs were taken on Kodak Ektachrome HC400 films. Haematoxylin/eosin-stained sections were analysed under light using the same microscope.

EM. Two AZ/10-infected I. ricinus ticks were processed for EM to confirm the spirochaetal infection in the tick batch used. Briefly, the ticks were cut longitudinally using a razor blade under ice-cold fixative $[3.5 \%$ glutaraldehyde in Sørensen phosphate buffer $\left(0 \cdot 1 \mathrm{M} \mathrm{KH}_{2} \mathrm{PO}_{4}, 0 \cdot 1 \mathrm{M} \mathrm{Na}_{2} \mathrm{HPO}_{4}\right.$, $\mathrm{pH} 7 \cdot 4)$ ]. After $2 \mathrm{~h}$, the fixative was diluted by adding Sørensen phosphate buffer (buffer/fixative $4: 1$ ) and stored at $4{ }^{\circ} \mathrm{C}$ until the fixation process was completed. Over a period of $2 \mathrm{~h}$ the specimens were rinsed several times with buffer solution and post-fixed with $2 \%$ buffered $\mathrm{OsO}_{4}$ solution. After a further $2 \mathrm{~h}$, the specimens were again rinsed with the buffer (three times for $10 \mathrm{~min}$ each) and were then dehydrated using a graded ethanol series and transferred to Araldite using propylenoxide as an intermedium. Polymerization occurred at $65^{\circ} \mathrm{C}$. Sectioning was performed with a Leica ultracut UCT (Wetzlar) using a diamond knife. Ultrathin sections were transferred to Formvar-covered copper grids. Sections were double-stained with uranyl acetate and lead citrate according to Reynolds (1963). EM-prepared tick sections were examined with a Zeiss EM 10CR transmission electron microscope.

\section{RESULTS}

\section{PCR and dot-blot hybridization}

The lower detection limit of the genus-specific amplification protocol was about 5-10 micro-organisms. Using an artificial DNA mixture containing rare templates (1 pg) from different Borrelia genospecies, the targets were detected even in the presence of a 100-fold excess of templates representing other genospecies. However, in cases of only weak amplicons, reamplification was necessary (data not shown) to increase the signal intensity in the subsequent analysis: in dot-blot hybridization experiments, LB-group-specific oligo-

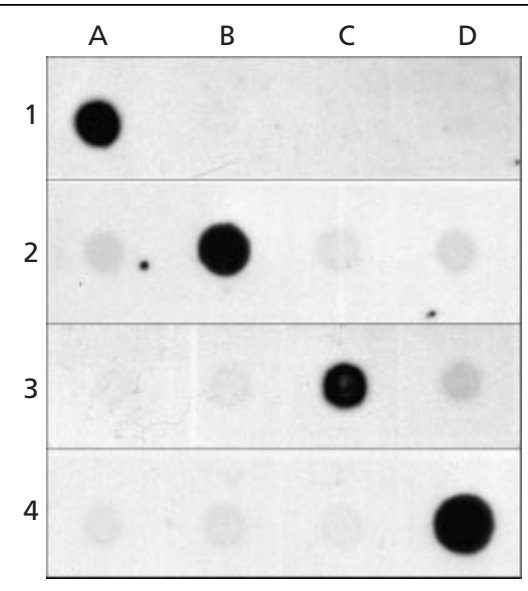

Fig. 1. Dot-blot hybridization of a membrane using LB-groupspecific oligonucleotide probes labelled with digoxigenin. DNA of four Borrelia control strains, $B$. burgdorferi ss $B 31^{\top}(A), B$. afzelii PKo (B), B. valaisiana VS116 ${ }^{\top}$ (C) and B. garinii A (D), was PCR-amplified using the genus-specific primer set Borr0/Borr4 and transferred to the membrane. Lanes 1-4 were then probed with BbV1, BaV1, BV and BgV1, respectively. 
Table 3. $P C R$ analysis of unfed $I$. ricinus nymphs which took their larval blood meal on gerbils in vivo-infected with $B$. afzelii and $B$. burgdorferi ss

\begin{tabular}{|lcccc|}
\hline $\begin{array}{l}\text { Infection } \\
\text { trial* }\end{array}$ & $\begin{array}{c}\text { PCR- } \\
\text { positive }\end{array}$ & \multicolumn{2}{c|}{ Dot-blot hybridization } & $\begin{array}{c}\text { Mixed } \\
\text { infection }\end{array}$ \\
\cline { 3 - 4 } & & BaV1-positive & BbV1-positive & \\
\hline A & 12 & 5 & 10 & 3 \\
B & 17 & 17 & 0 & 0 \\
\hline
\end{tabular}

*A, three gerbils first fed on by B. afzelii-infected I. ricinus nymphs and $27 \mathrm{~d}$ later by B. burgdorferi ssinfected I. scapularis nymphs; B, three gerbils first fed on by B. burgdorferi ss-infected I. scapularis nymphs and $45 \mathrm{~d}$ later by $B$. afzelii-infected I. ricinus nymphs. Eighteen ticks were tested in both trials.

Table 4. Specificity of oligonucleotide probes assessed by FISH

\begin{tabular}{|c|c|c|c|c|c|c|}
\hline $\begin{array}{l}\text { Spirochaetal } \\
\text { strain }\end{array}$ & reBaV1 & reBbV1 & $\mathrm{reBgV1}$ & $\mathrm{reBV}$ & Borr4 & EUB338 \\
\hline B. afzelii $\mathrm{PKo}$ & + & - & - & - & + & + \\
\hline B. burgdorferi ss $\mathrm{B} 31^{\mathrm{T}}$ & - & + & - & - & + & + \\
\hline B. garinii A & - & - & + & - & + & + \\
\hline B. valaisiana $\mathrm{VS} 116^{\mathrm{T}}$ & - & - & - & + & + & + \\
\hline B. hermsii HS1 & - & + & - & - & + & + \\
\hline $\begin{array}{l}\text { T. denticola ATCC } \\
33521\end{array}$ & - & - & - & - & - & + \\
\hline
\end{tabular}
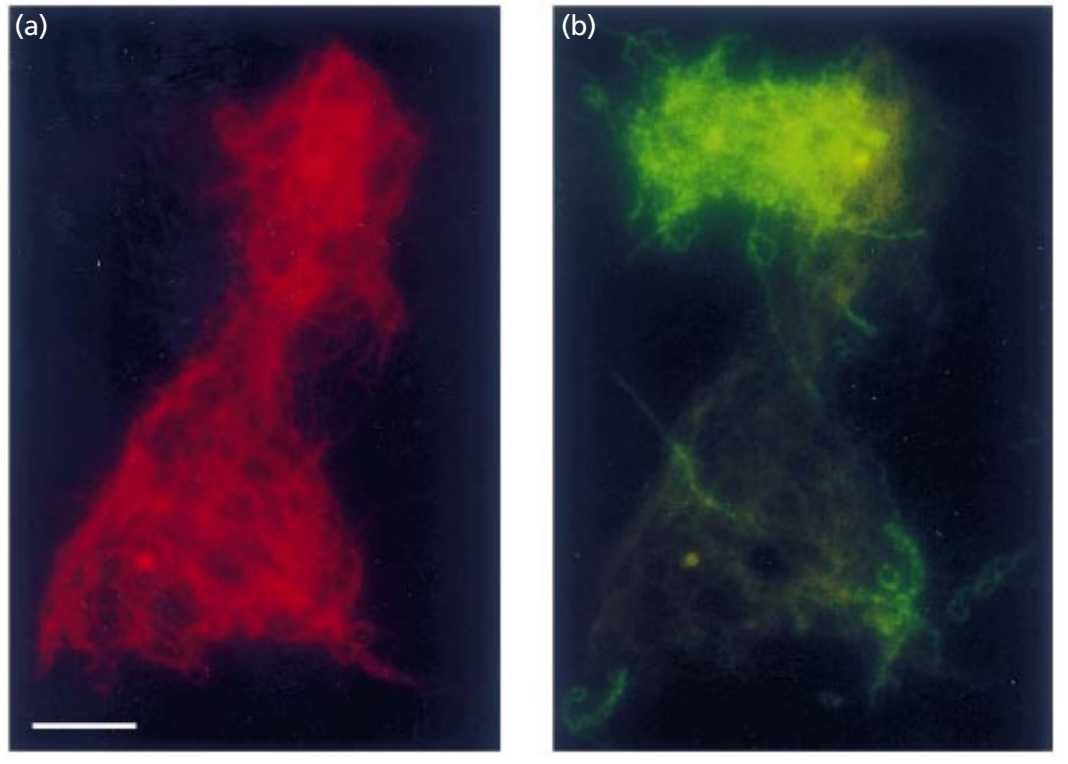

Fig. 2. FISH on an artificial mixture of $B$. afzelii (PKo) and $B$. burgdorferi ss $\left(\mathrm{B} 31^{\top}\right)$ using two probes simultaneously: reBaV1Cy3 (red) and reBbV1-fluorescein (green). (a) B. afzelii, (b) B. burgdorferi ss. Bar, $20 \mu \mathrm{m}$.

nucleotide probes were used to identify the respective amplicons (Fig. 1).

\section{Mixed infection in ticks}

Two series of infections were performed to produce gerbils double-infected with B. afzelii and B. burgdorferi ss. Putatively mixed-infected xenodiagnostic ticks showed an Borrelia infection rate of $100 \%$ as analysed by IFA. The resultant unfed nymphs were analysed by PCR and dot-blot hybridization at least 5 months after post-larval repletion; however double-infected ticks were rarely found (Table 3). Interestingly, in most cases the genospecies which was used in the second of two infection steps on the gerbil was detected in the xenodiagnostic ticks. The apparent rarity of mixed 
infected nymphs in our experiments prevented the planned inclusion of some of them in the FISH study.

\section{FISH for direct visualization of borreliae}

Oligonucleotide probes Borr4 and EUB338, complementary to semi-conserved and conserved regions of the $16 \mathrm{~S}$ rRNA, respectively, as well as probes specific within the group of LB-associated genospecies, reBaV1, reBbV1, reBgV1 and reBV, reacted with the appropriate control strains (Table 4, a representative example in Fig. 2a, b).

A strong and bleaching-stable orange-yellow signal was observed in tick sections using the two Cy3 fluorescencelabelled probes, Borr4 and reBaV1. B. afzelii cells mainly clustered conspicuously adjacent to midgut epithelial cells (Fig. 3b-e). The typical spirochaetal morphotype (Fig. 4) was found in five out of six putatively B. afzeliipositive I. ricinus nymphs. Borreliae could not be detected in the salivary glands nor in other tick tissues, for example muscles or the central ganglion. Multiple target labelling by simultaneous use of Borr4/Cy3 and $\mathrm{reBaV} 1 / \mathrm{Cy} 3$ did not result in an enhancement of the fluorescence signal. Due to the low signal-to-noise ratio, all attempts to visualize borreliae in ticks using fluorescein- or FluoX-labelled oligonucleotide probes failed (data not shown). However, autofluorescence of certain tick tissue structures allowed good histological orientation in the gross tick anatomy (Fig. 3a). Spirochaetes were not detected in any of the Borrelia-negative ticks.

As compared to tick tissues, the autofluorescence intensity was much lower in the gerbil skin sections, resulting in an excellent visualization of single spirochaetes, even with the FluoX-labelled oligonucleotide probe EUB338 (Fig. 5a, b). Borreliae were found mainly in the intercellular space of the lower fat cell layer close to subcutaneous muscles. Only a few borreliae were detected in biopsy sections (8 out of 22) taken directly from the tick attachment site. In contrast, all skin sections analysed $(n=6)$ taken $1.5 \mathrm{~cm}$ away from the tick-bite site - originally designed as negative controls contained 5-15 single spirochaetal cells per section situated adjacent to the muscle cell layer, suggesting a rather fast migration of the borreliae within the fat cell layer towards deeper parts of the skin.

\section{Ultrastructural analysis}

To confirm the results of the FISH on tick whole-body sections, EM was performed on individual I. ricinus nymphs derived from the identical tick batch. The ultrastructural analysis revealed that the I. ricinus batch used was highly infected. B. afzelii cells were found in high numbers intracellularly in the midgut epithelium but also in the midgut lumen (Fig. 6). Infection of salivary glands could not be demonstrated. Spirochaetes were usually cross-sectioned; longitudinally sectioned cells exhibiting the typical spiral morphotype only rarely occurred.

\section{DISCUSSION}

An easy way to detect borreliae in ticks is by either darkfield microscopy (e.g. Burgdorfer et al., 1982; Piesman et al., 1991) or direct immunofluorescence assay on crushed tick samples (Kahl et al., 1998b). Both methods are reliable, easy to perform in large series, and give good semi-quantitative results. Given the higher sensitivity and the possibility of storing the slides for several months, the direct or IFA can be considered as the method of choice to determine Borrelia infection in ticks. In principle, it allows the specific detection of Borrelia genospecies and detection of outer-surface protein expression when appropriate monoclonal antibodies are applied (Wilske et al., 1993, 1995; Fingerle et al., 1995; Masuzawa et al., 1996).

However, more sophisticated techniques are required to investigate the spatial distribution of borreliae within the tick. Furthermore, the in toto preparation of tick organs, for example salivary glands and midgut, without cross-contamination (Piesman, 1995) is not only extremely time-consuming but also requires careful controls. In the past, the distribution of B. burgdorferi sl within Ixodes vectors has been studied by several authors: by light microscopy using either Giemsa stain (Burgdorfer et al., 1982), silver dyes (e.g. Benach et al., 1987; Lebet \& Gern, 1994) or fluorescence-labelled antibodies (e.g. Piesman et al., 1986; de Silva \& Fikrig, 1995; Coleman et al., 1997; Leuba-Garcia et al., 1998), and also by EM (Burgdorfer et al., 1989; Zung et al., 1989; Zhu, 1998a, b). Although high magnification in the latter method allows resolution of most cellular details, for example the epithelial cells of the Malpighian tubules, EM is not suited for large-scale series. Furthermore, bacteria such as Borrelia genospecies cannot be differentiated by morphological criteria. EM seems to be more sensitive when compared to FISH. This could be due to the fact that EM mainly shows cross-sectioned spirochaetes which were seen in sections applied to FISH as well, but they cannot be identified with certainty even when showing a strong fluorescence signal (arrow in Fig. 4). On the other hand, in salivary glands no borreliae could be detected using FISH; unfortunately in this respect FISH could not be confirmed by EM, because in EM no salivary glands could be shown. They were probably lost during fixation of the ticks which were divided into two halves for EM embedding. However, assuming that a sufficient number of samples and sections are analysed, FISH seems to be well suited to study, for example, the distinct infection rate of the salivary glands in I. ricinus versus I. scapularis. Depending on the specific purpose of a particular study, each of the above-mentioned methods can be applied to detect spirochaetes in parts of a particular tick organ, or in relation to connective tissues when sections are prepared.

The purpose of the present study was to visualize borreliae in longitudinally in toto-sectioned I. ricinus ticks and to analyse the spatial distribution of the spirochaetes within different tick tissues. Demonstration 


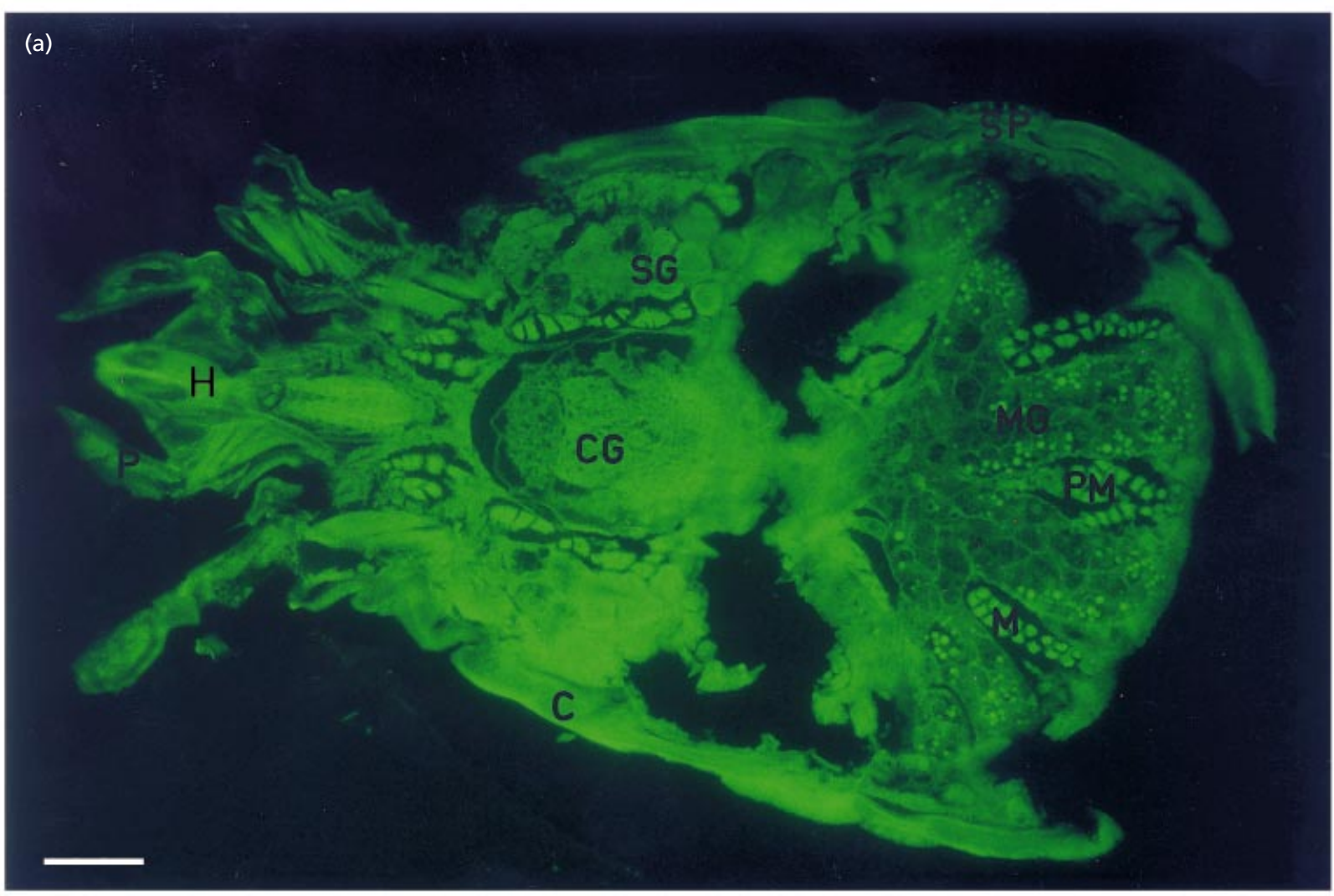

(b)
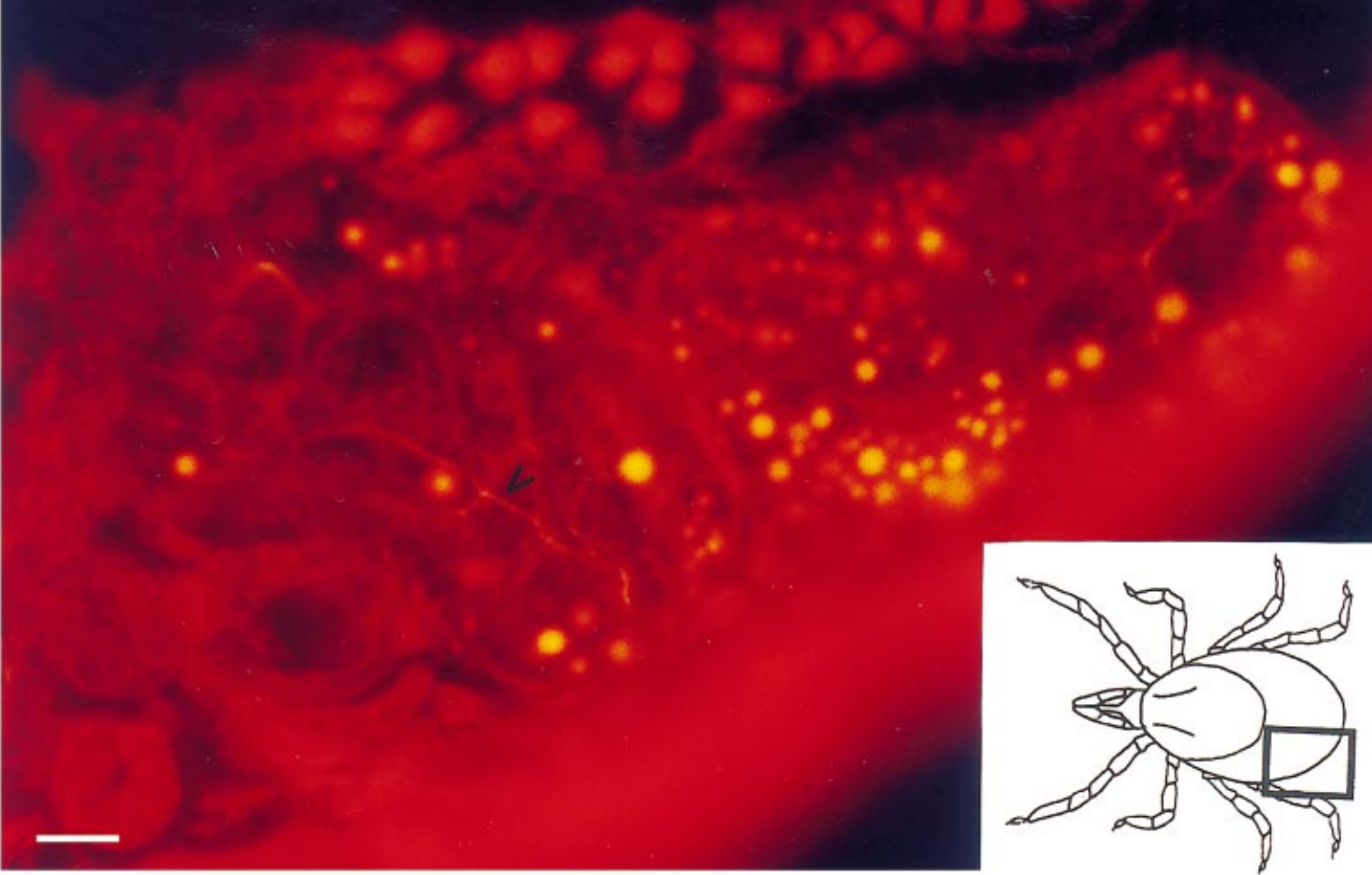

Fig. 3. For legend see page 1433. 
(c)

(d)

Fig. 3. For legend see facing page. 


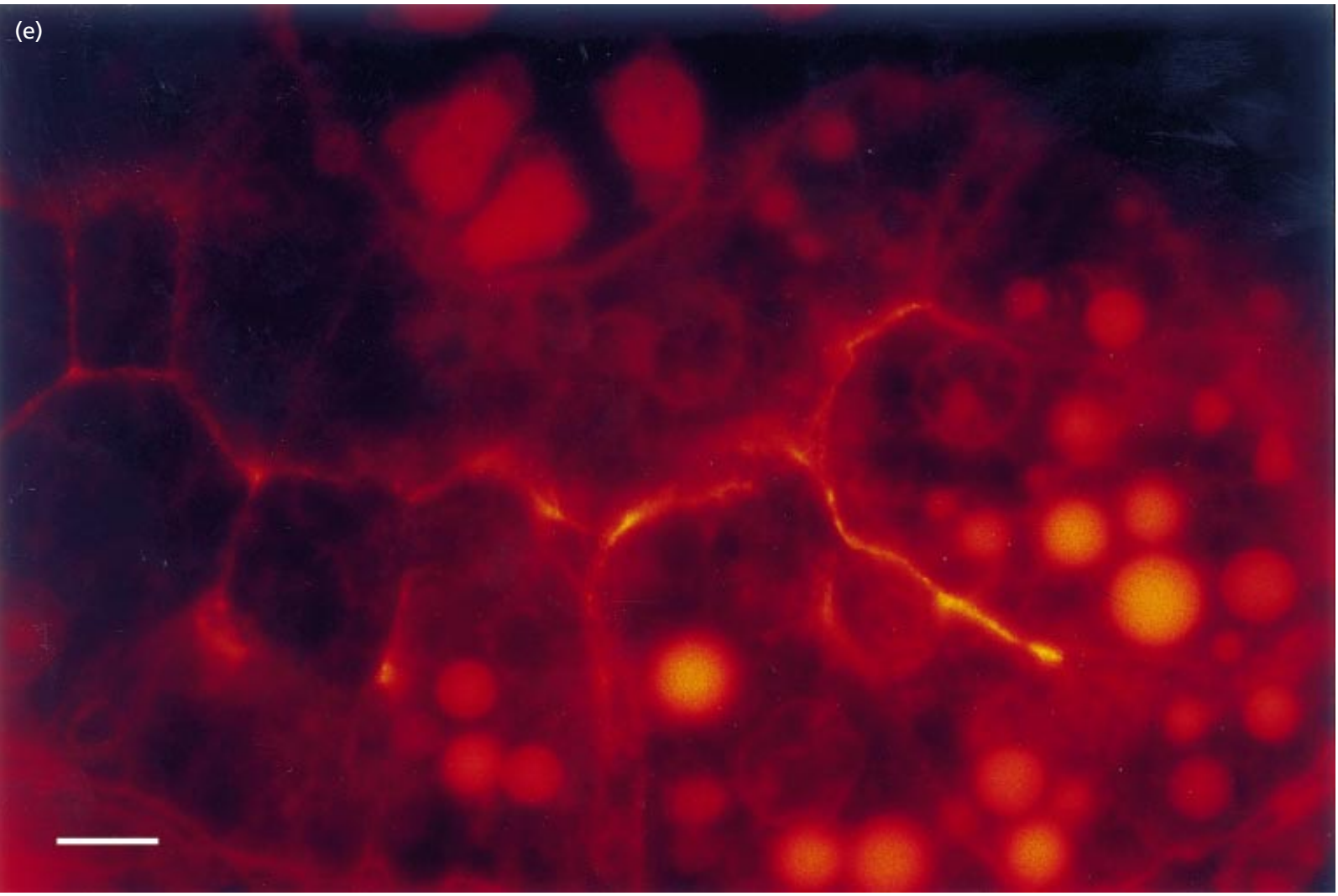

Fig. 3. Detection of borreliae by FISH in whole-body sections of an $I$. ricinus-nymph ( $2 \cdot 5$ months post-ecdysis), infected with $B$. afzelii AZ/10 during the larval blood meal. FISH was carried out using the Bacteria-specific probe EUB338fluorescein and the Borrelia genus-specific probe Borr4-Cy3 (b-d) or the B. afzelii-specific probe reBaV1-Cy3 (e). (a) Autofluorescence of a longitudinal-horizontally sectioned whole $l$. ricinus nymph. Note the opened cuticle at the posterior end for the entry of the fixative and embedding solutions. Tissue autofluorescence reveals the histology of the tick. P, palps; H, hypostome; CG, central ganglion; SG, salivary glands; $M$, pre-transversal muscles; PM, posterio-median muscles; MG, midgut; C, cuticle; SP, spiracular plate. (b) Posterio-lateral part of the tick section (see inset). Parts of the midgut are apparently separated by cross-sectioned pre-transversal muscles (at the upper border of the picture). The distinct orange-yellow line (arrowhead) within the midgut indicates a cluster of borreliae. (c) Detail of (b) showing a high resolution micrograph of the midgut borreliae. (d) Large numbers of intercellularly located borreliae clustering adjacent to the midgut epithelial cells. (e) Section of an AZ/10-infected I. ricinus nymph. Identification of $B$. afzelii within the tick midgut using the $B$. afzelii-specific probe reBaV1-Cy3. Bars: (a) $100 \mu \mathrm{m}$, (b) $20 \mu \mathrm{m}$, (c-e) $5 \mu \mathrm{m}$.

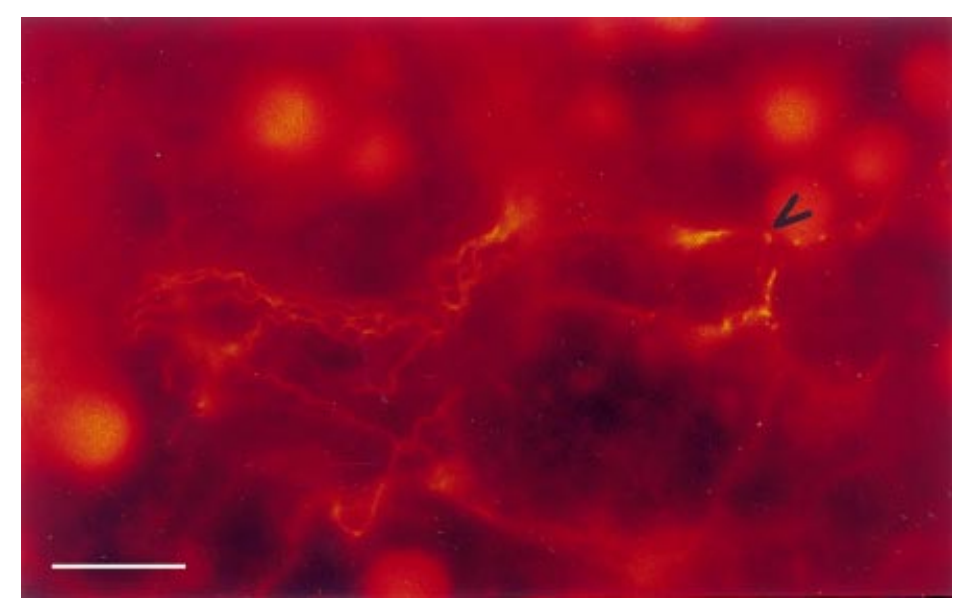

Fig. 4. Section of the same tick individual as in Fig. 3(a-d). The probes Borr4-Cy3 and EUB338-fluorescein were used. Clear visualization of the spirochaetal morphotype in one optical section within the tick midgut. Strong fluorescence signal of cross-sectioned borreliae (arrowhead) does not allow the unequivocal detection of spirochaetes. Bar, $5 \mu \mathrm{m}$. 

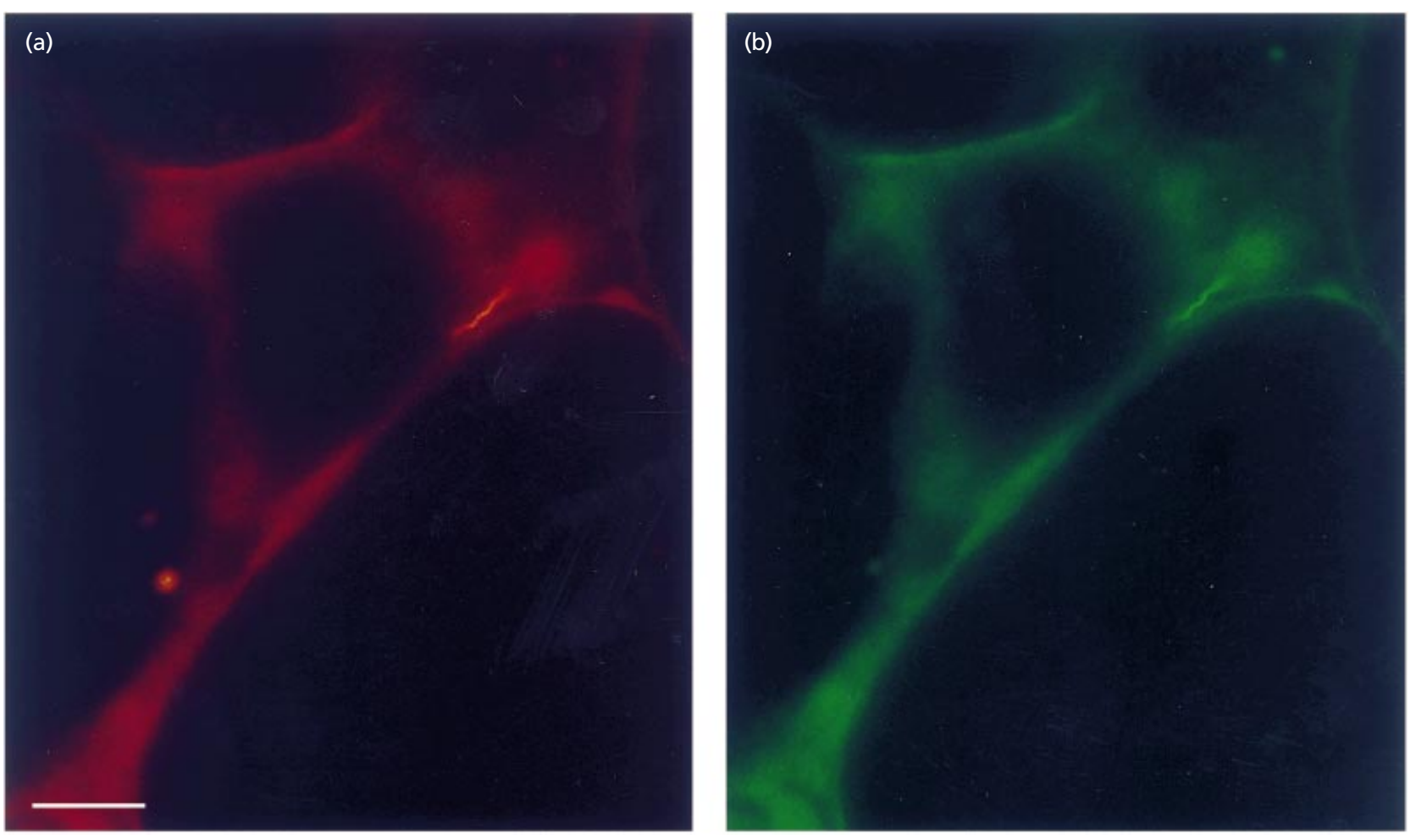

Fig. 5. Borrelia cell in a gerbil skin punch biopsy. FISH using the Borrelia genus-specific probe Borr4-Cy3 (a) and the bacteria phylotype-specific probe EUB-Fluox (b) showing a single spirochaete in the intercellular space between fat cells. Bar, $5 \mu \mathrm{m}$

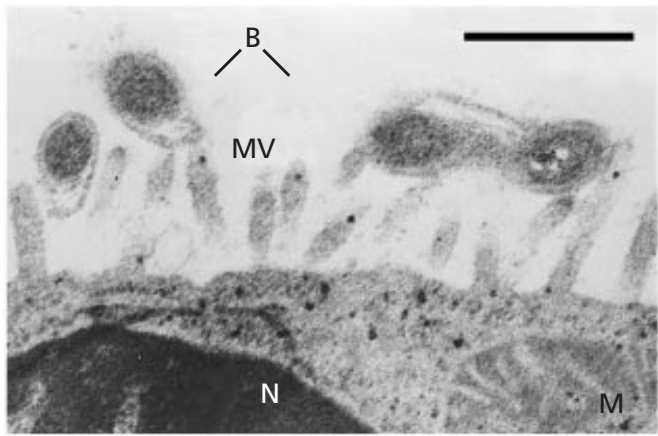

Fig. 6. Ultrastructure of a $B$. afzelii-infected $I$. ricinus nymph ( 2.5 months post-ecdysis). Borreliae in the lumen of the midgut close to the microvillus border. $B$, borreliae; $M$, mitochondria; MV, microvilli; N, nucleolus. Bar, $0.5 \mu \mathrm{m}$.

of the borrelial morphotype was excellent in FISH experiments since the cells were exclusively visualized lying within one optical section of the sample. FISH on resin-embedded sections is well suited for the simultaneous study of the presence, localization and identity of a borrelial infection within a tick. However, since this depends upon the proper entry of the fixative and embedding resin into the tick, not all organs may be visible in all sections. Inadequately embedded ticks or engorged ticks with insufficient penetration of embedding solutions consistently disintegrated during sectioning. Due to the autofluorescence of certain tick tissue structures and a relatively poor green signal resulting in a low signal-to-noise ratio, visualization of borreliae using fluorescein- or FluoX-labelled probes (EUB338, Borr4) was not successful and further fluorescent dyes should be tested for their suitability in FISH experiments on tick sections. The advantage of the method described here is the excellent preservation of the tissue architecture, its high specificity, i.e. the discrimination between genospecies, in combination with the exact localization of Borrelia cells in the tick tissues. This could be of considerable interest in mixedinfected ticks, which we failed to produce by stepwise feeding of infectious ticks on gerbils. It is known from previous studies that the Mongolian gerbil effectively transmits both $B$. afzelii and B. burgdorferi ss to feeding Ixodes ticks (O. Kahl, unpublished). In view of the fact that European I. ricinus populations very often harbour three or even four different Borrelia genospecies, it is intriguing that only a minority of the unfed nymphs carry a mixed infection. (Rijpkema et al., 1996; Kurtenbach et al., 1998; Richter et al., 1999; Humair et al., 1999; Gray et al., 2000). The question of which factors prohibit more frequent mixed Borrelia infections to occur in unfed nymphs deserves further study.

In conclusion, the combination of embedding tick samples in cold polymerizing resin and FISH using Cy3labelled probes results in an excellent signal-to-noise ratio. The Borrelia-specific probes described here are 
well suited to study borreliae in whole ticks and clinical specimens, for example on biopsies of patients with questionable LB as was reported by Stanek et al. (1990) on an endomyocardial biopsy specimen. Moreover, because of their good performance in PCR, the newly designed primers could be helpful in establishing a diagnostic assay for LB patients.

\section{ACKNOWLEDGEMENTS}

We are grateful to D. Fish for providing field-collected $I$. scapularis ticks, and to B. Wilske for OspA serotyping. We thank B. Graf and D. Postic for providing Borrelia strains. We would also like to thank R. Jonas and C. Hefenbrock for their excellent technical assistance. This work was supported by a Grant from the Deutsche Forschungsgemeinschaft (Ki 681/11) and the Humboldt-Universität zu Berlin.

\section{REFERENCES}

Alm, E. W., Oerther, D. B., Larsen, N., Stahl, D. A. \& Raskin, L. (1996). The oligonucleotide probe database. Appl Environ Microbiol 62, 3557-3559.

Amann, R., Binder, B. J., Olson, R. J., Chisholm, S. W., Devereux, R. \& Stahl, D. A. (1990). Combination of $16 \mathrm{~S}$ rRNA-targeted oligonucleotide probes with flow cytometry for analyzing mixed microbial populations. Appl Environ Microbiol 56, 1919-1925.

Amann, R., Snaidr, J., Wagner, M., Ludwig, W. \& Schleifer, K. H. (1996). In situ visualization of high genetic diversity in a natural microbial community. J Bacteriol 178, 3496-3500.

Barns, S. M., Fundyga, R. E., Jeffries, M. W. \& Pace, N. R. (1994). Remarkable archaeal diversity detected in a Yellowstone national park hot spring environment. Proc Natl Acad Sci USA 91, 1609-1613.

Benach, J. L., Coleman, J. L., Skinner, R. A. \& Bosler, E. M. (1987). Adult Ixodes dammini on rabbits: a hypothesis for the development and transmission of Borrelia burgdorferi. J Infect Dis 155, 1300-1306.

Berlau, J., Junker, U., Groh, A. \& Straube, E. (1998). In situ hybridisation and direct fluorescence antibodies for the detection of Chlamydia trachomatis in synovial tissue from patients with reactive arthritis. J Clin Pathol 51, 803-806.

Burgdorfer, W., Barbour, A. G., Hayes, S. F., Benach, J. L., Grunwaldt, E. \& Davis, J. P. (1982). Lyme disease - a tick-borne spirochetosis? Science 216, 1317-1319.

Burgdorfer, W., Hayes, S. F. \& Corwin, D. (1989). Pathophysiology of the Lyme disease spirochete, Borrelia burgdorferi, in ixodid ticks. Rev Infect Dis 11, suppl. 6, S1442-S1450.

Cobb, B. D. \& Clarkson, J. M. (1994). A simple procedure for optimising the polymerase chain reaction (PCR) using modified Taguchi methods. Nucleic Acids Res 22, 3801-3805.

Coleman, J. L., Gebbia, J. A., Piesman, J., Degen, J. L., Bugge, T. H. \& Benach, J. L. (1997). Plasminogen is required for efficient dissemination of B. burgdorferi in ticks and for enhancement of spirochetemia in mice. Cell 89, 1111-1119.

Fingerle, V., Hauser, U., Liegl, G., Branislav, P., Preac-Mursic, V. \& Wilske, B. (1995). Expression of outer surface proteins A and C of Borrelia burgdorferi in Ixodes ricinus. J Clin Microbiol 33, 1867-1869.

Forsgren, J., Samuelson, A., Ahlin, A., Jonasson, J., RynnelDagoo, B. \& Lindberg, A. (1994). Haemophilus influenzae resides and multiplies intracellularly in human adenoid tissue as demon- strated by in situ hybridization and bacterial viability assay. Infect Immun 62, 673-679.

Fritsche, T. R., Horn, M., Seyedirashti, S., Gautom, R. K., Schleifer, K. H. \& Wagner, M. (1999). In situ detection of novel bacterial endosymbionts of Acanthamoeba spp. phylogenetically related to members of the order Rickettsiales. Appl Environ Microbiol 65, 206-212.

Gern, L., Lebet, N. \& Moret, J. (1996). Dynamics of Borrelia burgdorferi infection in nymphal Ixodes ricinus ticks during feeding. Exp Appl Acarol 20, 649-658.

Gray, J. S., Robertson, J. N. \& Key, S. (2000). Limited role of rodents as reservoirs of Borrelia burgdorferi sensu lato in Ireland. Eur J Epidemiol 16, 101-103.

Harmsen, H. J., Wildeboer-Veloo, A. C., Raangs, G. C., Wagendorp, A. A., Klijn, N., Bindels, J. G. \& Welling, G. W. (2000). Analysis of intestinal flora development in breast-fed and formula-fed infants by using molecular identification and detection methods. J Pediatr Gastroenterol Nutr 30, 61-67.

Hogardt, M., Trebesius, K., Geiger, A. M., Hornef, M., Rosenecker, J. \& Heesemann, J. (2000). Specific and rapid detection by fluorescent in situ hybridization of bacteria in clinical samples obtained from cystic fibrosis patients. J Clin Microbiol 38, 818-825.

Humair, P. F., Rais, O. \& Gern, L. (1999). Transmission of Borrelia afzelii from Apodemus and Clethrionomys voles to Ixodes ricinus ticks: differential transmission pattern and overwintering maintenance. Parasitology 118, 33-42.

Jansen, G. J., Wildeboer-Veloo, A. C. M., Tonk, R. H. J., Franks, A. H. \& Welling, G. W. (1999). Development and validation of an automated, microscopy-based method for enumeration of groups of intestinal bacteria. J Microbiol Methods 37, 215-221.

Kahl, O., Janetzki, C., Gray, J. S., Stein, J. \& Bauch, R. J. (1992). Tick infection rates with Borrelia: Ixodes ricinus versus Haemaphysalis concinna and Dermacentor reticulatus in two locations in eastern Germany. Med Vet Entomol 6, 363-366.

Kahl, O., Janetzki-Mittmann, C., Gray, J. S., Jonas, R., Stein, J. \& de Boer, R. (1998a). Risk of infection with Borrelia burgdorferi sensu lato for a host in relation to the duration of nymphal Ixodes ricinus feeding and the method of tick removal. Zentbl Bakteriol 287, 41-52.

Kahl, O., Gern, L., Gray, J. S., Guy, E. C., Jongejan, F., Kirstein, F., Kurtenbach, K., Rijpkema, S. G. T. \& Stanek, G. (1998b). Detection of Borrelia burgdorferi sensu lato in ticks: immunofluorescence assay versus polymerase chain reaction. Zentbl Bakteriol 287, 205-210.

Korenberg, E. I. \& Moskvitina, H. G. (1996). Interrelationships between different Borrelia genospecies and their principal vectors. J Vector Ecol 21, 178-185.

Kurtenbach, K., Peacey, M., Rijpkema, S. G. T., Hoodless, A. N., Nuttall, P. A. \& Randolph, S. E. (1998). Differential transmission of the genospecies of Borrelia burgdorferi sensu lato by game birds and small rodents in England. Appl Environ Microbiol 64, 1169-1174.

Lebet, N. \& Gern, L. (1994). Histological examination of Borrelia burgdorferi infections in unfed Ixodes ricinus nymphs. Exp Appl Acarol 18, 177-183.

Lee, S. H., Malone, C. \& Kemp, P. F. (1993). Use of multiple $16 \mathrm{~S}$ rRNA-targeted fluorescent probes to increase signal strength and measure cellular RNA from natural planktonic bacteria. Mar Ecol Prog Ser 101, 193-201.

Leuba-Garcia, S., Kramer, M. D., Wallich, R. \& Gern, L. (1994). Characterization of Borrelia burgdorferi isolated from different 
organs of Ixodes ricinus ticks collected in nature. Zentbl Bakteriol 280, 468-475.

Leuba-Garcia, S., Martinez, R. \& Gern, L. (1998). Expression of outer surface proteins A and C of Borrelia afzelii in Ixodes ricinus ticks and in the skin of mice. Zentbl Bakteriol 287, 475-484.

Maiwald, M. (1996). Einsatz molekularbiologischer Methoden in der mikrobiologischen Diagnostik am Beispiel von Legionella species, Borrelia burgdorferi und des Whipple-Bakteriums. [Habilitationsschrift] Medizinische Fakultät Heidelberg, R.Karls-Universität.

Masuzawa, T., Wilske, B., Komikado, T. \& 7 other authors (1996). Comparison of OspA serotypes for Borrelia burgdorferi sensu lato from Japan, Europe and North America. Microbiol Immunol 40, 539-545.

Moter, A. \& Göbel, U. B. (2000). Fluorescence in situ hybridization (FISH) for direct visualization of microorganisms. J Microbiol Methods 41, 85-112.

Moter, A., Leist, G., Rudolph, R., Schrank, K., Choi, B.-K., Wagner, M. \& Göbel, U. B. (1998). Fluorescence in situ hybridization shows spatial distribution of as yet uncultured treponemes in biopsies from digital dermatitis lesions. Microbiology 144, 2459-2467.

Piesman, J. (1995). Dispersal of the Lyme disease spirochete Borrelia burgdorferi to salivary glands of feeding nymphal Ixodes scapularis (Acari: Ixodidae). J Med Entomol 32, 519-521.

Piesman, J., Mather, T. N., Telford, S. R., 3rd \& Spielman, A. (1986). Concurrent Borrelia burgdorferi and Babesia microti infection in nymphal Ixodes dammini. J Clin Microbiol 24, 446-447.

Piesman, J., Maupin, G. O., Campos, E. G. \& Happ, C. M. (1991). Duration of adult female Ixodes dammini attachment and transmission of Borrelia burgdorferi, with description of a needle aspiration isolation method. J Infect Dis 163, 895-897.

Reynolds, E. S. (1963). The use of lead citrate at high $\mathrm{pH}$ as an electron opaque stain in electron microscopy. J Cell Biol 17, 208-212.

Richter, D., Endepols, S, Ohlenbusch, A., Eiffert, H., Spielman, A. \& Matuschka, F.-R. (1999). Genospecies diversity of Lyme disease spirochetes in rodent reservoirs. Em Infect Dis 5, 291-296.

Rijpkema, S. G., Molkenboer, M. J., Schouls, L. M., Jongejan, F. \& Schellekens, J. F. (1995). Simultaneous detection and genotyping of three genomic groups of Borrelia burgdorferi sensu lato in Dutch Ixodes ricinus ticks by quaracterization of the amplified intergenetic spacer region between $5 \mathrm{~S}$ and $23 \mathrm{~S}$ rRNA genes. J Clin Microbiol 33, 3091-3095.

Rijpkema, S. G., Golubic, D., Molkenboer, M. J., Verbeek-De Fruif, N. \& Schellekens, J. F. (1996). Identification of four genomic groups of Borrelia burgdorferi sensu lato in Ixodes ricinus ticks collected in a Lyme borreliosis endemic region of northern Croatia. Exp Appl Acarol 20, 23-30.

Rijpkema, S. G., Tazelaar, D. J., Molkenboer, M. J., Noordhoek,
G. T., Plantinga, G., Schouls, L. M. \& Schellekens, J. F. (1997). Detection of Borrelia afzelii, Borrelia burgdorferi sensu stricto, Borrelia garinii and group VS116 by PCR in skin biopsies of patients with erythema migrans and acrodermatitis chronica atrophicans. Clin Microbiol Infect 3, 109-116.

Sambrook, J., Fritsch, E. F. \& Maniatis, T. (1989). Molecular Cloning: a Laboratory Manual, 2nd edn. Cold Spring Harbor, NY: Cold Spring Harbor Laboratory.

Schuppler, M., Wagner, M., Schön, G. \& Göbel, U. B. (1998). In situ identification of nocardioform actinomycetes in activated sludge using fluorescent rRNA-targeted oligonucleotide probes. Microbiology 144, 249-259.

de Silva, A. M. \& Fikrig, E. (1995). Growth and migration of Borrelia burgdorferi in Ixodes ticks during blood feeding. Am J Trop Med Hyg 53, 397-404.

Snaidr, J., Amann, R., Huber, I., Ludwig, W. \& Schleifer, K. H. (1997). Phylogenetic analysis and in situ identification of bacteria in activated sludge. Appl Environ Microbiol 63, 2884-2896.

Stanek, G., Klein, J., Bittner, R. \& Glogar, D. (1990). Isolation of Borrelia burgdorferi from the myocardium of a patient with longlasting cardiomyopathy. New Engl J Med 322, 249-252.

Trebesius, K., Harmsen, D., Rakin, A., Schmelz, J. \& Heesemann, J. (1998). Development of rRNA-targeted PCR and in situ hybridization with fluorescently labelled oligonucleotides for detection of Yersinia species. J Clin Microbiol 36, 2557-2564.

Wilske, B., Preac-Mursic, V., Göbel, U. B., Graf, B., Jauris, S., Soutschek, E., Schwab, E. \& Zumstein, G. (1993). An OspA serotyping system for Borrelia burgdorferi based on reactivity with monoclonal antibodies and OspA sequence analysis. J Clin Microbiol 31, 340-350.

Wilske, B., Jauris-Heipke, S., Lobentanzer, R., Pradel, I., PreacMursic, V., Rössler, D., Soutschek, E. \& Johnson, R. C. (1995). Phenotypic analysis of outer surface protein C (OspC) of Borrelia burgdorferi sensu lato by monoclonal antibodies: relationship to genospecies and OspA serotype. J Clin Microbiol 33, 103-109.

Zhu, Z. (1998a). Histological observation on Borrelia burgdorferi growth in naturally infected female Ixodes ricinus. Acarologia 2, $11-22$.

Zhu, Z. (1998b). Borrelia burgdorferi in replete nymphal Ixodes ricinus: a localization study using light and electron microscopy. Acarologia 2, 123-133.

Zung, J. L., Lewengrub, S., Rudzinska, M. A., Spielman, A., Telford, S. R. \& Piesman, J. (1989). Fine structural evidence for the penetration of the Lyme disease spirochete Borrelia burgdorferi through the gut and salivary tissue of Ixodes dammini. Can J Zool 67, 1737-1748.

Received 30 October 2000; revised 25 January 2001; accepted 12 February 2001. 